\title{
Effects of Fatty Acids on Accumulation and Secretion of Histamine in RBL-2H3 Cells and Leukotriene Release from Peritoneal Exudate Cells Isolated from Wistar Rats
}

\author{
Koji Yamada, Mitsuo Mori, Noritaka Matsuo, Kentaro Shoji, \\ Takashi Ueyama, and Michihiro Sugano \\ Laboratory of Food Science, Department of Food Science and \\ Technology, Faculty of Agriculture, Kyushu University, \\ Fukuoka 812-81, Japan
}

(Received December 4, 1995)

\begin{abstract}
Summary Effects of fatty acids on accumulation and secretion of histamine in rat basophilic leukemia RBL-2H3 cells and leukotriene release from peritoneal exudate cells isolated from Wistar rats were examined in relation to the manifestation of type $\mathrm{I}$ allergic reactions. When RBL-2H 3 cells were cultured for $24 \mathrm{~h}$ in the presence of $1 \mathrm{~mm}$ short chain fatty acids, a marked increase in histamine accumulation was observed, especially with butyric acid. In addition, Ca-ionophore A23187-stimulated histamine release was enhanced in the cells treated with $0.1 \mathrm{~mm}$ mono to hexa unsaturated fatty acids with 18 to 22 carbonchains. On the other hand, $\mathrm{LTB}_{4}$ release from rat peritoneal exudate cells was inhibited in the presence of polyunsaturated fatty acids, both $n-6$ and $n-3$, having more than 3 double bonds. Inhibitory activity was enhanced by an increase in the number of double bonds, and docosahexaenoic acid (DHA) exerted the highest activity with complete inhibition at $0.1 \mathrm{mM}$ and $35.5 \%$ inhibition even at $10 \mu \mathrm{M}$. A hydrophobic radical scavenger (9,10-diphenylanthracene) and two antioxidants (butyrated hydroxytoluene and $\alpha$-tocopherol) inhibited the production of $\mathrm{LTB}_{4}$, but hydrophilic counterparts (mannitol and ascorbic acid) did not. These results suggest that lipophilic anti-oxidative agents, as well as PUFA, inhibit the production of $\mathrm{LTB}_{4}$.

Key Words fatty acids, histamine, leukotriene, RBL-2H3 cells, rat peritoneal exudate cells, food allergy
\end{abstract}

Allergic reactions are usually classified into 4 types, and allergy against food proteins or airborne antigens is generally classified as type I (1). In the expression of type I allergy, induction of IgE specific to allergens, and release of chemical mediators, such as histamine or leukotriene (LT), are essential steps. During the past 40 years, the number of allergy patients has increased markedly in Japan, and 
it is believed that changes in eating style and living circumstances have strongly influenced the prevalence of allergy (2). During this period, the increase in protein uptake was less than 20\%, whereas the fat intake increased roughly 3-fold (3). Thus, it is reasonable to consider that the relationship between changes in eating habits and allergen intake help to explain the increase in allergic patients observed during this period.

Recently, it has been reported that some food components affect immune reactions. Bile acids in particular, which are secreted into the duodenum to help lipid absorption, behave as an allergy enhancing factor by stimulating IgE production and inhibiting IgA production of mesenteric lymph node lymphocytes in rats (4). In contrast, mediator release from basophils or mast cells has been reported to be suppressed by various food components such as flavonoids $(5,6)$, tea polyphenols $(7,8)$, flavorings (9) and polyunsaturated fatty acids (PUFA) (10-13).

PUFA can regulate a diverse range of biological functions, including immune reactions. Arachidonic acid $(n-6)$ is a substrate of lipoxygenase and gives 4-series LT which induce the expression of type I allergy. On the contrary, another $n-6$ $\gamma$-linolenic acid appears to be anti-allergenic $(14,15)$. In addition, $n$-3 PUFA, such as eicosapentaenoic (EPA) and docosahexaenoic (DHA) acids, appear to serve as inhibitors against type I allergy (10-13). In the present study, we examined the in vitro effects of various fatty acids on the accumulation and release of histamine from rat basophilic leukemia RBL-2H3 cells as well as LT release from rat peritoneal exudate cells (PEC) in order to generalize their modifying potential toward type I allergic reactions.

\section{MATERIALS AND METHODS}

Materials. Acetic $(2: 0)$, propionic $(3: 0)$, butyric $(4: 0)$, valeric $(5: 0)$, caproic $(6: 0)$, heptylic $(7: 0)$, caprilic $(8: 0)$, pelargonic $(9: 0)$, and capric $(10: 0)$ acids were purchased from Wako Pure Chemicals (Osaka, Japan). Sodium salts of lauric $(12: 0)$, myristic $(14: 0)$, palmitic $(16: 0)$, stearic $(18: 0)$, oleic $(18: 1 n-9)$, $\alpha$-linolenic (18:3n-3), and $\gamma$-linolenic (18:3n-6) acids were purchased from Funakoshi (Tokyo), arachidonic acid (20:4n-6), EPA $(20: 5 n-3)$, and DHA $(22: 6 n-3)$ from Sigma Chemical Co. (St. Louis, MO, USA), and linoleic acid (18:2n-6) from Nakalai Tesque Inc. (Kyoto, Japan). Free fatty acids were dissolved in dimethyl sulfoxide (DMSO) and sodium salts were dissolved in a phosphate-buffered saline containing $136.9 \mathrm{mM} \mathrm{NaCl}, 2.7 \mathrm{mM} \mathrm{KCl}, 8.1 \mathrm{mM} \mathrm{Na}_{2} \mathrm{HPO}_{4}$, and $1.5 \mathrm{mM} \mathrm{KH}_{2} \mathrm{PO}_{4}$ (pH. 7.4) (PBS). Water-soluble ascorbic acid (AsA) and mannitol were dissolved in PBS, whereas water-insoluble butyrated hydroxytoluene (BHT), $\alpha$-tocopherol, and 9,10 diphenylanthracene (DPA) were dissolved in DMSO. DPA was purchased from Sigma and the other antioxidants were purchased from Wako Pure Chemicals. Calcium ionophore A23187, $\mathrm{PGB}_{2}$ and $\mathrm{LTB}_{4}$ were products from Sigma. Histamine dihydrochloride and $o$-phthalaldehyde were purchased from Wako Pure Chemicals and trypsin from Difco (Detroit, MI, USA). 
Cells and cell culture. Rat basophilic leukemia RBL-2H3 cells were obtained from the Japanese Cancer Research Resource Bank (Tokyo) and cultured with RPMI 1640 medium supplemented with 10\% fetal bovine serum (FBS) (Intergen, NY, USA). Randomly proliferating RBL-2H3 cells were inoculated at the cell density of $1 \times 10^{6}$ cells/dish, in $10 \mathrm{ml}$ plastic dishes (Nunc, Roskilde, Denmark), and cultured for $24 \mathrm{~h}$. Then, one thousandth of the total volume of the DMSO solutions containing various fatty acids was added to the culture and cultured for $24 \mathrm{~h}$. The cells were trypsinized with $0.005 \%$ trypsin dissolved in PBS, containing $0.5 \mathrm{~mm}$ EDTA, washed once with PBS containing $0.5 \mathrm{mM}$ EDTA, and then resuspended in a Tyrode buffer (137 mM NaCl-2.7 mM KCl-1.8 $\mathrm{mM} \mathrm{CaCl}_{2}-1.1 \mathrm{mM} \mathrm{MgCl}_{2}-11.9 \mathrm{~mm}$ $\mathrm{NaHCO}_{3}-\mathrm{NaH}_{2} \mathrm{PO}_{4}, \mathrm{pH} 7.2$ ) supplemented with $0.9 \mathrm{mM} \mathrm{CaCl}$ at the cell density of $1 \times 10^{6} \mathrm{cells} / \mathrm{ml}$. One group of cell suspensions were sonicated to measure their intracellular histamine content. Another group of suspensions was incubated for 20 $\min$ at $37^{\circ} \mathrm{C}$, with or without $5 \mu \mathrm{M} \mathrm{A} 23187$, to measure Ca-ionophore-stimulated or spontaneous histamine release. Histamine contents in the cell homogenate or the suspension medium were determined according to the method of Shore et al. (16), with only slight modifications (8). Relative intracellular histamine content was calculated by dividing the values of fatty acid-treated cells with those of control cells. A23187-stimulated histamine release (\%) was calculated by the following formula; (A23187-stimulated release - spontaneous release) $\times 100 /$ (intracellular content-spontaneous release).

Rat PEC were isolated from male 8-week-old Wistar rats given a commercial pellet chow (Seiwa Experimental Animals, Fukuoka, Japan), as described previously (8), and $2 \times 10^{6}$ cells were stimulated for $20 \mathrm{~min}$ at $37^{\circ} \mathrm{C}$ with $5 \mu \mathrm{M}$ A23187 in the presence of PUFA. LT content in the culture medium was measured according to the method of Powell (17) with only slight modifications (8).

Statistics. Data were analyzed by Duncan's new multiple range test to evaluate significant differences (18).

\section{RESULTS}

Effects of fatty acids on accumulation and secretion of histamine in $R B L-2 H 3$ cells

RBL-2H3 cells were cultured in the presence of $1 \mathrm{mM}$ short- and medium-chain fatty acids (SCFA and MCFA) with various carbon numbers for $24 \mathrm{~h}$ and then intracellular histamine content was measured to determine the effect on histamine accumulation. As shown in Table 1, there was a marked elevation of cellular histamine levels in the cells treated with SCFA, such as propionic (61\% increase), butyric ( $129 \%$ increase), and valeric (50\% increase) acids. On the other hand, the intracellular histamine levels decreased slightly in the presence of peralgonic acid (25\% decrease) while capric acid exerted a lethal effect.

Next, the cells were incubated for $20 \mathrm{~min}$ in Tyrode buffer containing $0.9 \mathrm{mM}$ $\mathrm{CaCl}_{2}$, with or without $\mathrm{A} 23187$, and histamine contents in the buffer were examined to determine the cells' histamine releasing activity. Percentage of histamine 
Table 1. Effect of short and medium chain fatty acids on accumulation and secretion of histamine in RBL-2H3 cells of Wistar rats.

\begin{tabular}{lcc}
\hline \multicolumn{1}{c}{ Fatty acids } & $\begin{array}{c}\text { Relative intracellular } \\
\text { histamine content }\end{array}$ & $\begin{array}{c}\text { A23187-stimulated } \\
\text { histamine release }(\%)\end{array}$ \\
\hline None & $1.00 \pm 0.01^{\mathrm{a}}$ & $71.1 \pm 1.2^{\mathrm{a}}$ \\
Acetic $(2: 0)$ & $0.93 \pm 0.04^{\mathrm{a}}$ & $54.1 \pm 2.2^{\mathrm{b}}$ \\
Propionic $(3: 0)$ & $1.61 \pm 0.09^{\mathrm{b}}$ & $58.1 \pm 2.7^{\mathrm{bd}}$ \\
Butyric $(4: 0)$ & $2.29 \pm 0.06^{\mathrm{c}}$ & $51.4 \pm 3.4^{\mathrm{b}}$ \\
Valeric $(5: 0)$ & $1.50 \pm 0.03^{\mathrm{b}}$ & $48.0 \pm 4.8^{\mathrm{b}}$ \\
Capronic (6:0) & $1.01 \pm 0.04^{\mathrm{a}}$ & $47.4 \pm 4.2^{\mathrm{b}}$ \\
Heptylic (7:0) & $0.94 \pm 0.04^{\mathrm{a}}$ & $51.1 \pm 2.8^{\mathrm{b}}$ \\
Caprylic $(8: 0)$ & $1.00 \pm 0.04^{\mathrm{a}}$ & $27.4 \pm 4.9^{\mathrm{c}}$ \\
Pelargonic (9:0) & $0.75 \pm 0.04^{\mathrm{d}}$ & $67.1 \pm 6.2^{\mathrm{ad}}$ \\
Capric $(10: 0)$ & dead & dead \\
\hline
\end{tabular}

Results are the $\mathbf{M} \pm \mathrm{SE}(n=3)$ and ${ }^{\mathrm{a}-\mathrm{d}}$ values not sharing a common letter are significantly different at $p<0.05$.

Table 2. Effect of long chain fatty acids on accumulation and secretion of histamine in RBL-2H3 cells of Wistar rats.

\begin{tabular}{lcc}
\hline \multicolumn{1}{c}{ Fatty acids } & $\begin{array}{c}\text { Relative intracellular } \\
\text { histamine content }\end{array}$ & $\begin{array}{c}\text { A23187-stimulated } \\
\text { histamine release }(\%)\end{array}$ \\
\hline None & $1.00 \pm 0.08^{\mathrm{ac}}$ & $88.3 \pm 2.8^{\mathrm{a}}$ \\
Lauric $(12: 0)$ & $1.28 \pm 0.01^{\mathrm{b}}$ & $87.5 \pm 3.5^{\mathrm{a}}$ \\
Myristic $(14: 0)$ & $1.16 \pm 0.01^{\mathrm{ab}}$ & $91.5 \pm 1.9^{\mathrm{a}}$ \\
Palmitic $(16: 0)$ & $0.97 \pm 0.04^{\mathrm{c}}$ & $84.7 \pm 2.8^{\mathrm{a}}$ \\
Stearic $(18: 0)$ & $0.85 \pm 0.07^{\mathrm{c}}$ & $88.3 \pm 5.9^{\mathrm{a}}$ \\
\hline
\end{tabular}

Results are the $\mathrm{M} \pm \mathrm{SE}(n=3)$ and ${ }^{\mathrm{a}-\mathrm{c}}$ values not sharing a common letter are significantly different at $p<0.05$.

released by A23187 stimulation decreased from $71 \%$ in untreated control cells to $54 \%, 58 \%, 51 \%$, and $48 \%$ in the cells treated with acetic, propionic, butyric, and valeric, respectively. However, the amounts of histamine released from the cells treated with butyric, propionic, and valeric acids were higher than that of control cells, reflecting higher intracellular histamine contents. A similar decrease in the histamine release rate was observed for the cells treated with MCFA, especially in the cells treated with caprylic acid. Since intracellular histamine content did not increase in these cells, the amounts of histamine released by A23187 stimulation significantly decreased in those cells treated with MCFA.

Since long chain fatty acids (LCFA) at $1 \mathrm{~mm}$ exerted as strong a cytotoxicity as capric acid, RBL- $2 \mathrm{H} 3$ cells were cultured with $0.1 \mathrm{~mm}$ LCFA for $24 \mathrm{~h}$. As shown in Table 2, histamine accumulation was slightly enhanced in the presence of lauric (28\% increase) and myristic (16\% increase, not significant) acids, but slightly suppressed in the presence of palmitic (3\% decrease, not significant) and 
stearic (15\% decrease, not significant) acids. However, histamine release rate was not affected by the treatment with LCFA.

In the case of unsaturated fatty acids (UFA), the cells were treated with 0.1 mM UFA, at the highest concentration in which no UFA exerted any cytotoxicity. As shown in Table 3, all UFA weakly enhanced histamine accumulation to varying degrees. Increased rates were $27 \%, 32 \%, 14 \%$, and $32 \%$ in oleic, linoleic, $\gamma$ linolenic, and arachidonic acids, respectively, and 7\%, 20\%, and $16 \%$ in $\alpha$ linolenic, EPA, and DHA, respectively. Similarly, the proportion of histamine released by this stimulation increased slightly in the cells treated with UFA, except for oleic acid. Reflecting these increases in intracellular histamine content and release rate, the amount of histamine released by A23187 stimulation increased $24 \%$ in $n-9$ oleic acid, 39\%, 23\%, and $42 \%$ in $n-6$ linoleic, $\gamma$-linolenic, and arachidonic acids, and 20\%, 28\%, and 33\% in $n-3 \alpha$-linolenic acid, EPA and DHA, respectively.

Effect of unsaturated fatty acids on $\mathrm{LTB}_{4}$ release from rat peritoneal exudate cells

Since RBL-2H3 cells could not produce detectable amounts of LT, rat PEC were used to examine the LT production regulating activity of UFA. Though unstimulated PEC did not produce detectable amounts of $\mathrm{LTB}_{4}$, they released $\mathrm{LTB}_{4}$ as a major product after A23187 stimulation (Fig. 1). Thus, the effect of UFA on $\mathrm{LTB}_{4}$ release was examined under this situation. When PEC were stimulated with $\mathrm{Ca}$-ionophore in the presence of $0.1 \mathrm{mM}$ UFA, oleic and linoleic acids did not affect $\mathrm{LTB}_{4}$ production (Fig. 2). On the other hand, PUFA with more than 3 double bonds significantly inhibited $\mathrm{LTB}_{4}$ release. The decreases in $\mathrm{LTB}_{4}$ release were $42 \%$ in $\alpha$-linolenic acid, 57\% in $\gamma$-linolenic acid, 33\% in arachidonic acid, $86 \%$ in EPA, and almost 100\% with DHA. As shown in Fig. 1, the level of an unidentified eicosanoid eluted at $15.62 \mathrm{~min}$ was higher than that of $\mathrm{LTB}_{4}$ eluted at $26.05 \mathrm{~min}$ in the presense of EPA. In the presence of DHA, the peak corresponds to $\mathrm{LTB}_{4}$ at

Table 3. Effect of unsaturated fatty acids on accumulation and secretion of histamine in RBL-2H3 cells of Wistar rats.

\begin{tabular}{lcc}
\hline \multicolumn{1}{c}{ Fatty acids } & $\begin{array}{c}\text { Relative intracellular } \\
\text { histamine content }\end{array}$ & $\begin{array}{c}\text { A23187-stimulated } \\
\text { histamine release }(\%)\end{array}$ \\
\hline None & $1.00 \pm 0.02^{\mathrm{a}}$ & $78.3 \pm 0.7^{\mathrm{a}}$ \\
Oleic $(18: 1 n-9)$ & $1.27 \pm 0.05^{\mathrm{bd}}$ & $77.8 \pm 1.4^{\mathrm{a}}$ \\
Linoleic $(18: 2 n-6)$ & $1.32 \pm 0.02^{\mathrm{b}}$ & $86.1 \pm 0.3^{\mathrm{b}}$ \\
$\alpha$-Linolenic $(18: 3 n-3)$ & $1.07 \pm 0.01^{\mathrm{c}}$ & $92.9 \pm 3.5^{\mathrm{bc}}$ \\
$\gamma$-Linolenic $(18: 3 n-6)$ & $1.14 \pm 0.02^{\mathrm{ce}}$ & $89.0 \pm 2.4^{\mathrm{bc}}$ \\
Arachidonic $(20: 4 n-6)$ & $1.32 \pm 0.06^{\mathrm{b}}$ & $89.5 \pm 4.5^{\mathrm{bc}}$ \\
EPA $(20: 5 n-3)$ & $1.20 \pm 0.02^{\mathrm{de}}$ & $94.4 \pm 1.4^{\mathrm{c}}$ \\
DHA $(22: 6 n-3)$ & $1.16 \pm 0.03^{\mathrm{ce}}$ & $94.6 \pm 1.1^{\mathrm{c}}$ \\
\hline
\end{tabular}

Results are the $\mathrm{M} \pm \mathrm{SE}(n=3)$ and ${ }^{\mathrm{a}-\mathrm{e}}$ values not sharing a common letter are significantly different at $p<0.05$. 


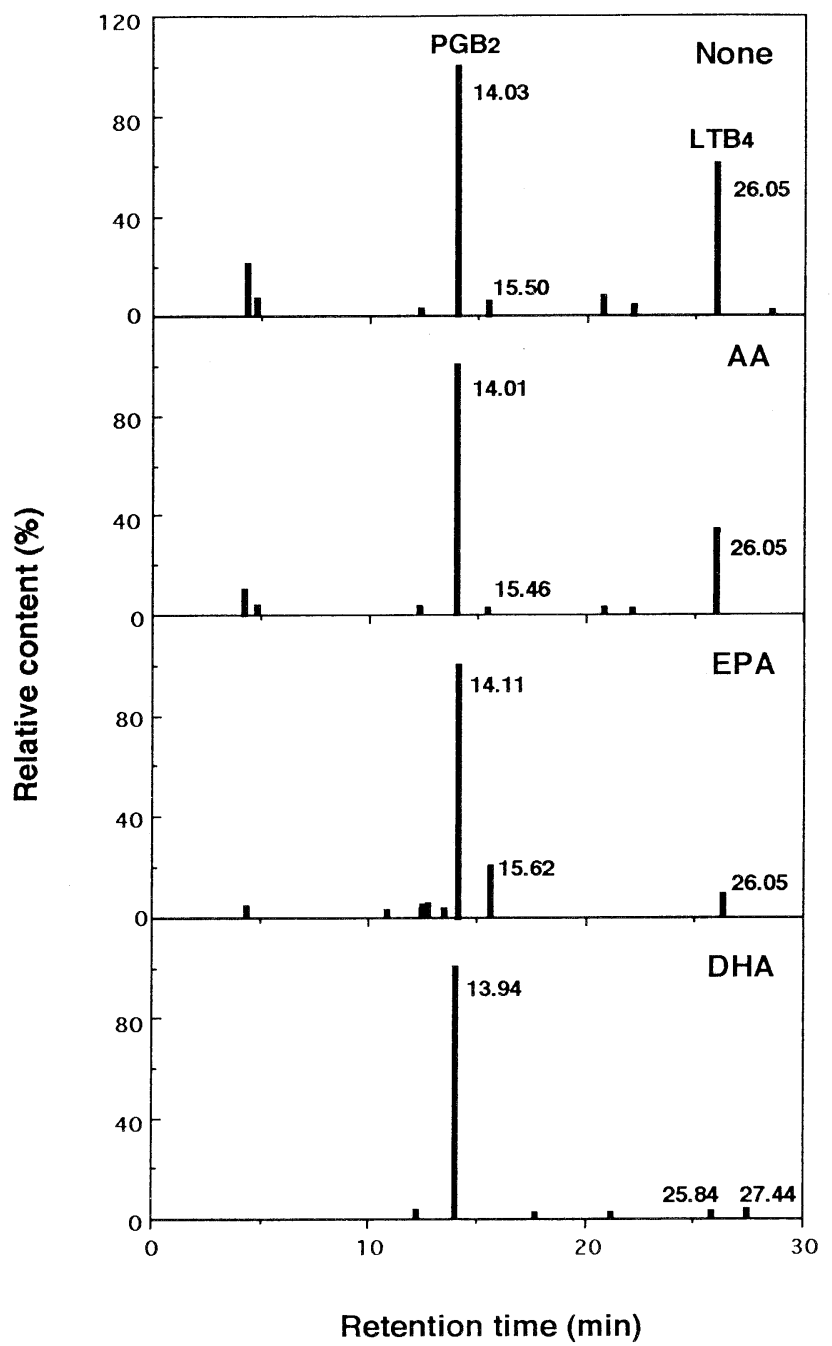

Fig. 1. Elution profiles of leukotriene released from rat peritoneal exudate cells.

26.05 disappeared, and two small unidentified peaks were detected at 25.8 and 27.4 min, respectively.

Next, the dose-dependent effect of UFA on $\mathrm{LTB}_{4}$ release was examined (Fig. 3). Arachidonic acid added to Tyrode buffer did not enhance $\mathrm{LTB}_{4}$ production at either 1 or $10 \mu \mathrm{M}$, but significantly inhibited the production at $100 \mu \mathrm{M}$. EPA and DHA exerted an inhibitory tendency even at $1 \mu \mathrm{M}$, and then significantly inhibited $\mathrm{LTB}_{4}$ production at $10 \mu \mathrm{M}$. At all concentrations, DHA exerted stronger inhibitory activity than EPA.

When the cells were stimulated with A23187 in the presence of $100 \mu \mathrm{M}$ of an 


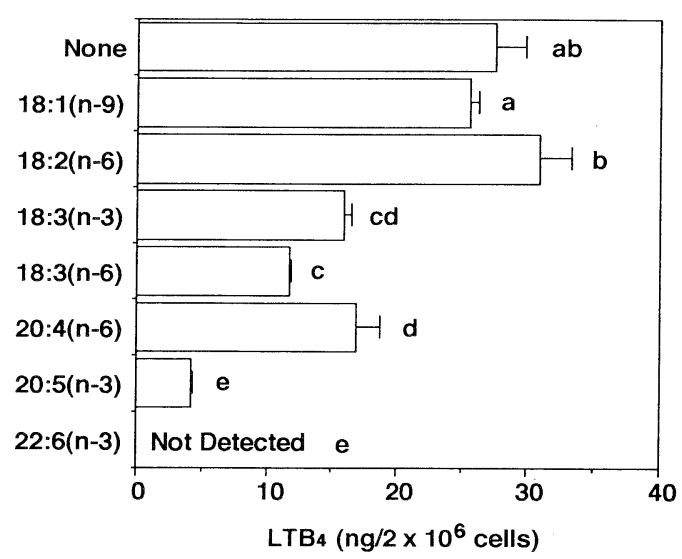

Fig. 2. Effect of unsaturated fatty acids on $\mathrm{LTB}_{4}$ production from rat peritoneal exudate cells. Results are the $\mathbf{M} \pm \mathbf{S E}(n=3)$ and values not sharing a common letter are significantly different at $p<0.05$.

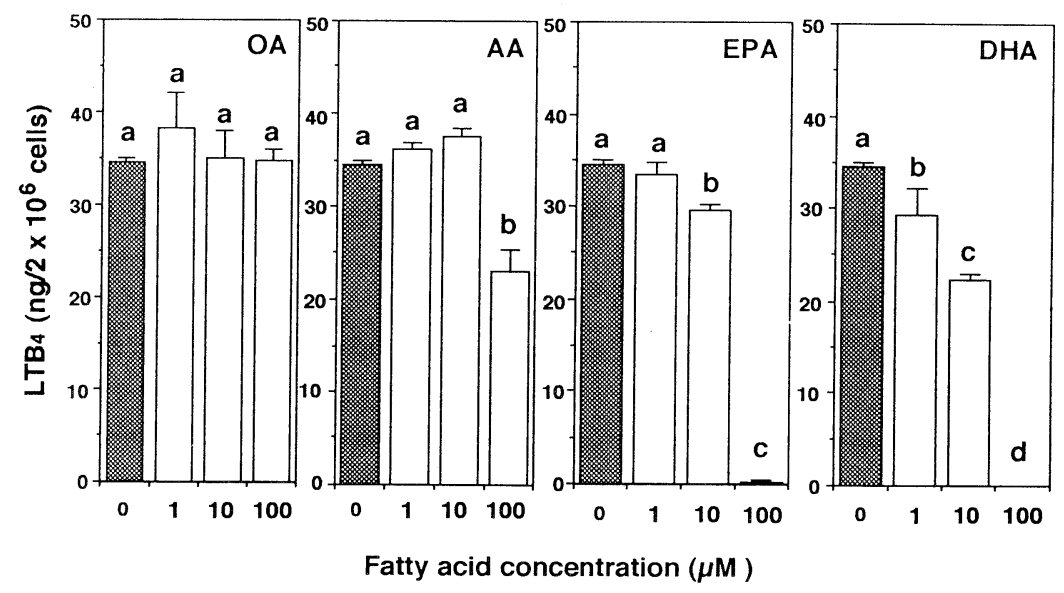

Fig. 3. Dose-dependent effect of unsaturated fatty acids on $\mathrm{LTB}_{4}$ production from rat peritoneal exudate cells. Results are the $\mathbf{M} \pm \mathbf{S E}(n=3)$ and values not sharing a common letter are significantly different at $p<0.05$.

$\mathrm{OH}$ radical scavenger (mannitol) or a singlet oxygen scavenger (DPA), the latter weakly inhibited the production of $\mathrm{LTB}_{4}$ (Table 4). A hydrophilic antioxidant, ascorbic acid, did not affect $\mathrm{LTB}_{4}$ production, but two hydophobic antioxidants (BHT, $\alpha$-tocopherol) exerted a strong inhibitory effect. These radical scavengers and antioxidants could not cancel the inhibition of $\mathrm{LTB}_{4}$ production induced by 100 $\mu \mathrm{M}$ DHA. 
Table 4. Effect of antioxidants and radical scavengers on $\mathrm{LTB}_{4}$ production-inhibitory activity of DHA.

\begin{tabular}{lccc}
\hline \multicolumn{1}{c}{ Additives } & PBS & DMSO & $\begin{array}{c}\text { LTB }_{4} \text { content } \\
\left(\mathrm{ng} / 2 \times 10^{6} \text { cells }\right)\end{array}$ \\
\hline PBS & + & - & $28.1 \pm 2.2^{\mathrm{a}}$ \\
Ascorbic acid & + & - & $28.0 \pm 1.1^{\mathrm{a}}$ \\
Mannitol & + & - & $28.4 \pm 1.0^{\mathrm{a}}$ \\
DMSO & - & + & $29.3 \pm 1.7^{\mathrm{a}}$ \\
BHT & - & + & not detected \\
$\alpha$-Tocopherol & - & + & $5.3 \pm 0.8^{\mathrm{b}}$ \\
DPA & - & + & $20.8 \pm 1.4^{\mathrm{c}}$ \\
\hline
\end{tabular}

PEC of Wistar rats $\left(2 \times 10^{6}\right.$ cells $)$ were stimulated with A23187 in the presence of 1 $\mu \mathrm{M}$ of antioxidants or radical scavengers with or without $100 \mu \mathrm{M}$ DHA. Since no $\mathrm{LTB}_{4}$ was detectable in the presence of DHA, the table shows the data without DHA. Results are the $\mathrm{M} \pm \mathrm{SE}(n=3)$ and ${ }^{\mathrm{a}-\mathrm{c}}$ values not sharing a common letter are significantly different at $p<0.05$.

\section{DISCUSSION}

We studied the effect of fatty acids on histamine release from rat RBL-2H3 cells in relation to their activities in modifying allergic reactions and found that SCFA enhanced histamine accumulation in the cells. Butyric acid exerted the strongest activity, followed by propionic and valeric acids, through $24-\mathrm{h}$ treatment with $1 \mathrm{~mm}$ fatty acids. SCFA have been reported to affect diverse cellular activities, such as proliferation $(19,20)$, morphology $(21,22)$, and various differentiated functions $(23,24)$. In all cases, butyrate exerts the strongest biological effect at concentrations around $1 \mathrm{mM}$. SCFA are fermentation products of dietary fibers by gut bacteria, and are quickly absorbed from the colon (25). Butyric acid is one of the major SCFA and its level is around $20 \mathrm{mmol} / \mathrm{kg}$ in the human colon (25). These results suggest a possibility that high fiber diets enhance type I allergic reactions.

The effects of other saturated and unsaturated fatty acids on histamine accumulation were negligible under our conditions ( $24 \mathrm{~h}$ cultivation with 0.1 or 1 mM fatty acids; at highest concentrations of no cytotoxicity). However, most fatty acids exerted a tendency of enhancing A23187-stimulated histamine release. Human plasma fatty acid levels have been reported to be $0.3-0.6 \mathrm{~mm}$ in their normal state and to exceed $1 \mathrm{~mm}$ in their starved or stressed state (26). These results suggest that plasma levels of fatty acids can modify histamine release from basophils or mast cells.

LT is a group of the chemical mediators which induces type I allergy. We showed here that various PUFA with more than 3 double bonds suppressed $\mathrm{LTB}_{4}$ release from rat PEC, and that this suppressing activity increased with a corresponding increase in the number of double bonds. EPA has already been reported 
to suppress LT production (11-13). Though $\mathrm{LTB}_{4}$ is produced through lipoxygenase-catalyzed oxidation of arachidonic acid, the addition of arachidonic acid to Tyrode buffer at concentrations below $10 \mu \mathrm{M}$ did not enhance $\mathrm{LTB}_{4}$ production, and actually exerted an inhibiting tendency at $100 \mu \mathrm{M}$. EPA is also oxidized with lipoxygenase to give 5-series of LT such as $\mathrm{LTB}_{5}$ and $\mathrm{LTC}_{5}$. $\mathrm{LTB}_{5}$ has been reported to elute after the peak of internal standard $\mathrm{PGB}_{2}$ and before the $\mathrm{LTB}_{4}$ peak under our HPLC system (27). The eicosanoid with a similar retention time was detected only in the presence of EPA and it may represent $\mathrm{LTB}_{5}$. This suggests that extracellular EPA is incorporated into the cells and utilized for LT production. The inhibition of $\mathrm{LTB}_{4}$ production by arachidonic acid suggests that the incorporation rate of arachidonic acid is not so rapid in enhancing $\mathrm{LTB}_{4}$ production and that it inhibits some step of a series of reactions for $\mathrm{LTB}_{4}$ production.

The detection of $\mathrm{LTB}_{5}$ in the presence of EPA suggests that it inhibits the production of 4-series LT through the production of 5-series LT. However, DHA exerted the strongest inhibitory activity and eicosanoid production was universally suppressed in the presence of DHA. This suggests that PUFA inhibit $\mathrm{LTB}_{4}$ production by themselves. A hydrophobic radical scavenger (DPA) and two antioxidants (BHT and $\alpha$-tocopherol) inhibited LTB $_{4}$ production similarly, although their hydrophilic counterparts did not affect the process. These results suggest that hydrophobic anti-oxidative agents as well as PUFA inhibit the production of $\mathrm{LTB}_{4}$.

This work was partly supported by the Special Coordination Funds for Promoting Science and Technology of the Science and Technology Agency of Japan.

\section{REFERENCES}

1) Metcalfe, D. D. (1991): Food allergy. Curr. Opin. Immunol., 3, 881-886.

2) Kobayashi, S. (1987): Recent allergy studies. Kagaku to Seibutsu, 25, 540-545 (in Japanese).

3) National Nutrition Survey of Japan (-1993), (1995): Health Service Bureau Annual Report, Ministry of Health and Welfare Japan, Daiichi Shuppan, Tokyo.

4) Lim, B. O., Yamada, K., and Sugano, M. (1994): Effect of bile acids and lectins on immunoglobulin production in rat mesenteric lymph node lymphocytes. In Vitro Cell. Develop. Biol., 30A, 407-413.

5) Baumann, J., von Bruchhausen, F., and Wurm, G. (1980): Flavonoids and related compounds as inhibitors of arachidonic acid peroxidation. Prostaglandins, 20, 627639.

6) Corvazier, E., and Maclouf, J. (1985): Interference of some flavonoids and nonsteroidal anti-inflammatory drugs with oxidative metabolism of arachidonic acid by human platelets and neutrophils. Biochim. Biophys. Acta, 835, 315-321.

7) Maeda, Y., Yamamoto, M., Masui, T., Sugiyama, K., Yokota, M., Nakagomi, K., Tanaka, H., Takahashi, I., and Kobayashi, T. (1989): Inhibitory effect of tea extracts on histamine release from mast cells. J. Food Hyg., 30, 295-299 (in Japanese). 
8) Matsuo, N., Yamada, K., Yamashita, K., Shoji, K., Mori, M., and Sugano, M. (1995): Inhibitory effect of tea polyphenols on histamine and leukotriene $\mathrm{B}_{4}$ release from rat peritoneal exudate cells. In Vitro Cell. Develop. Biol., 32, 340-344.

9) Arakawa, T., Shibata, M., Hosomi, K., Watanabe, T., Honma, Y., Kawasumi, K., and Takeuchi, Y. (1992): Anti-allergic effects of peppermint oil, chicle and jelutong. $J$. Food Hyg., 33, 569-575 (in Japanese).

10) Prescott, S. M. (1984): The effect of eicosapentaenoic acid on leukotriene B production by human neutrophils. J. Biol. Chem., 259, 7615-7621.

11) Terano, T., Salmon, J. A., and Moncada, S. (1984): Effect of orally administered eicosapentaenoic acid (EPA) on the formation of leukotriene $\mathrm{B}_{4}$ and leukotriene $\mathrm{B}_{5}$ by rat leukocytes. Biochem. Pharmacol., 33, 3071-3076.

12) Lee, T. H., Hoover, R. L., Williams, J. D., Sperling, R. I., Ravalese, J., III, Spur, B. W., Robinson, D. R., Corey, E. J., Lewis, R. A., and Austen, K. F. (1985): Effect of dietary enrichment of eicosapentaenoic and docosahexaenoic acids on in vitro neutrophil and monocyte leukotriene generation and neutrophil function. N. Engl. J. Med., 312, 1217-1224.

13) Thien, F. C. K., Hallsworth, M. P., Soh, C., and Lee, T. H. (1993): Effect of exogenous eicosapentaenoic acid on generation of leukotriene $\mathrm{C}_{4}$ and leukotriene $\mathrm{C}_{5}$ by calcium ionophore-activated human eosinophils in vitro. J. Immunol., 150, 3546-3552.

14) Schalin-Karrila, M., Mattila, L., Jansen, C. T., and Uotila, P. (1987): Evening primrose oil in the treatment of atopic eczema: effect on clinical status, plasma phospholipid fatty acids and circulating blood prostaglandins. Br. J. Dermatol., 117, 11-19.

15) Lovell, C. R., Burton, J. L., and Horrobin, D. F. (1981): Treatment of atopic eczema with evening primrose oil. Lancet, i, 278-279.

16) Shore, P. A., Burkhalter, A., and Cohn, V. H. (1959): A method for the fluorometric assay of histamine in tissues. J. Pharmacol. Exp. Ther., 127, 182-186.

17) Powell, W. S. (1987): Precolumn extraction and reversed-phase high-pressure liquid chromatography of prostaglandins and leukotrienes. Anal. Biochem., 164, 117-131.

18) Duncan, D. B. (1955): Multiple range and multiple F test. Biometrics, 11, 1-42.

19) D’Anna, J. A., Tobey, R. A., and Gurly, L. R. (1980): Concentration-dependent effect of sodium butyrate in Chinese hamster cells: cell-cycle progression inner-histone acetylation, histone $\mathrm{H} 1$ dephosphrylation, and induction of $\mathrm{H} 1$-like protein. Biochemistry, 19, 2656-2671.

20) Matsuo, N., Yamada, K., Noda, S., Yamashita, K., Okuda, A., Kimura, G., and Sugano, M. (1994): Reversible proliferation arrest of rat 3Y1 fibroblasts and selective killing of Simian virus transformed derivation of $3 Y 1$ by short-chain fatty acids. Int. J. Oncol., 5, 655-660.

21) Ginsburg, E., Salomon, D., Sreevalsen, T., and Freese, E. (1973): Growth inhibition and morphological changes caused by lipophilic acids in mammalian cells. Proc. Natl. Acad. Sci. USA, 70, 2457-2461.

22) Yamada, K., Sasaki, M., and Kimura, G. (1985): Effect of sodium butyrate on actin distribution in rat 3 Y1 fibroblasts in monolayer culture. J. Cell. Physiol., 125, 235-242.

23) Henneberry, R. C., and Fishman, P. H. (1976): Morphological and biochemical differentiation in HeLa cells. Effect of cycloheximide on butyrate-induced process formation and ganglioside metabolism. Exp. Cell Res., 103, 55-62. 
24) Fallon, R. J., and Cox, R. P. (1980): Cell cycle analysis of sodium butyrate and hydroxyurea, inducers of ectopic hormone production in HeLa cells. J. Cell. Physiol., 100, 251-262.

25) Macfarlene, G. T., and Cummings, J. H. (1991): The colonic flora, fermentation, and large bowel digestive function, in The Large Intestine: Physiology, Pathology and Disease, ed. by Phillips, S. F., Pengerton, J. H., and Shorter, R. G., Raven Press, New York, pp. 51-92.

26) Calder, P. C., Bond, J. A., Harvey, D. J., Gordon, S., and Newsholme, E. A. (1990): Uptake and incorporation of saturated and unsaturated fatty acids into macrophage lipids and their effect upon macrophage adhesion and phagocytosis. Biochem. J., 269, 807-814.

27) Schacky, C., von Fahrer, C., and Fischer, S. (1990): Catabolism of leukotriene $B_{5}$ in humans. J. Lipid Res., 31, 1831-1838. 